\title{
GERD CORRELATION BETWEEN CLINICAL SYMPTOMS AND ENDOSCOPIC FINDINGS: A STUDY OF 200 PATIENTS
}

\author{
N. A. V. S. K. Ravi Kumar'1, M. V. V. Gandhi², G. Sri Harsha ${ }^{3}$
}

${ }^{1}$ Assistant Professor, Department of Medicine, Andhra Medical College, Visakhapatnam.

${ }^{2}$ Assistant Professor, Department of Medicine, Andhra Medical College, Visakhapatnam.

3Postgraduate Student, Department of Medicine, Andhra Medical College, Visakhapatnam.

\begin{tabular}{l}
\hline ABSTRACT \\
BACKGROUND \\
Gastro Eesophageal Reflux Disease (GERD) is a common disorder. The numerous complications of chronic GERD, especially \\
Barrett's oesophagus necessitate adequate diagnosis and treatment of this common entity. This study was designed to analyse the \\
spectrum of GERD based on presenting symptoms and endoscopic findings, and analyse the contributory factors.
\end{tabular}

\section{MATERIALS AND METHODS}

A prospective study was conducted on the patients visiting the Medicine OPD/Gastroenterology Clinic at Andhra Medical College Hospital, King George Hospital from January 2014 to January 2015 with symptoms suggestive of GERD. The clinical symptoms, possible risk factors and endoscopic findings were studied and analysed.

\section{RESULTS}

Totally, 200 patients were studied. The number of male patients (66\%) were more than females. Most of the patients were in the age group 30-60 years (74.5\%). The most common symptoms were heartburn (92\%), regurgitation (90\%), belching (96\%), abdominal pain $(50.5 \%)$ and water brash (31\%). History of smoking was present in $22 \%$ and alcohol consumption in $15.5 \%$. BMI was $<25$ in $90 \%$ of the cases whereas on considering the waist-to-hip ratio (WHR) $36.5 \%$ were classified as obese. $39 \%$ of the patients had endoscopy positive GERD and 5\% had Barrett's oesophagus (BE). There was one patient each with oesophageal adenocarcinoma and oesophageal candidiasis. 9\% patients had hiatal hernia and 7\% showed associated lesions like gastritis/duodenitis/ulcers. Among the symptoms, only acid regurgitation and water brash showed significant correlation with endoscopic findings. Alcohol intake had positive association with oesophagitis. Obesity indicated by increased Body Mass Index (BMI) and Waist Hip Ratio (WHR) showed correlation with oesophageal lesions.

\section{CONCLUSION}

Symptomatic GERD may not be associated with endoscopic evidence of oesophagitis and reinforced the fact that NERD is a common entity, which forms a considerable proportion of patients seeking medical attention for reflux symptoms. However, since the patients with Barrett's oesophagus are at a higher risk of developing adenocarcinoma, it is suggested that all patients with reflux symptoms should be subjected to upper gastrointestinal (UGI) endoscopy and biopsy.

\section{KEYWORDS}

Gastrooesophageal Reflux Disease (GERD), Upper GI Endoscopy, Barrett's Oesophagus.

HOW TO CITE THIS ARTICLE: Kumar NAVSKR, Gandhi MVV, Harsha GS. GERD correlation between clinical symptoms and endoscopic findings: A study of 200 patients. J. Evolution Med. Dent. Sci. 2016;5(81):6038-6041, DOI: 10.14260/jemds/2016/1363

\section{INTRODUCTION}

Gastrooesophageal reflux is a common disorder, affecting up to $45 \%$ of persons at some time during the course of a month, 20 to $30 \%$ of persons at least weekly with equal gender distribution. Frequent or severe symptoms of gastrooesophageal reflux disease are associated with time lost from work and impaired health related quality of life.

The prevalence of GERD is estimated to be $7.5 \%$ in Indians. Possible reason for the low prevalence include low fat diet, low body mass index and high prevalence of Helicobacter pylori infection.

Financial or Other, Competing Interest: None.

Submission 23-07-2016, Peer Review 05-08-2016,

Acceptance 07-08-2016, Published 07-10-2016.

Corresponding Author:

Dr. N.A.V.S.K. Ravi Kumar,

Flat \# SF2, Viceroy Heights,

Plot No. 11-9-33/6, Daspalla Hills,

Visakhapatnam-530003.

E-mail: gandhimanchu@gmail.com

DOI: $10.14260 /$ jemds/2016/1363
An important concept emerging from the consensus process is that of GERD being a spectrum disease that can run from symptomatic GERD through the potential complications of oesophagitis, haemorrhage and stricture formation, to Barrett's oesophagus and oesophageal adenocarcinoma. Endoscopy has become a major tool to assess the final consequences of GERD. This particular study was designed to analyse the spectrum of GERD based on presenting symptoms and endoscopic findings.

\section{AIMS AND OBJECTIVES}

1. To study the clinical spectrum of GERD and correlate between the severity of symptoms and UGI endoscopic findings in patients with GERD.

2. To study the incidence of Barrett's oesophagus.

\section{MATERIALS AND METHODS}

Source of Data

A prospective study on adult patients visiting Gastro Clinic/Medicine Outpatient Department at King George Hospital, Visakhapatnam from the period January 2014 to January 2015 with symptoms of GERD. 


\section{Method of Collection of Data}

All patients attending Gastro Clinic/Medicine Outpatient Department at King George Hospital with symptoms of heartburn, acid regurgitation, belching, dyspepsia and water brash were taken for the study. A clinical history including age, sex, duration and severity of symptoms, possible aetiological factors like tobacco/alcohol use, other co-existing medical illness, treatment taken for reflux symptoms were evaluated and entered in a proforma.

\section{Grading}

The hallmark symptoms of GERD i.e., heartburn and regurgitation were graded into mild, moderate and severe based on the following scale.

Grade 1: Mild; symptoms present once in a week.

Grade 2: Moderate; symptoms present most days in a week.

Grade 3: Severe; symptoms present daily.

A detailed physical examination was done. BMI was calculated by noting the height and weight of each patient using the formula BMI=Weight in $\mathrm{Kg} /(\text { Height in metres })^{2}$. Waist-to-hip ratio of all the patients was also calculated and classified accordingly as overweight and normal.

\section{Parameters Studied}

1. Age, sex.

2. Risk Factors.

3. BMI and Waist-to-hip ratio.

4. UGI endoscopy findings and biopsy reports.

\section{Inclusion Criteria}

1. Patients with symptoms of GERD-heartburn, Acid regurgitation.

2. Belching, Dyspepsia, Water brash and Dyspepsia.

\section{Exclusion Criteria}

1. Patients who had prior UGI endoscopy and found to have diseases like Carcinoma Oesophagus, Peptic ulcer, Barrett's Oesophagus.

2. Inability to complete UGI endoscopy.

3. Failure to give informed consent.

\section{Statistical Analysis}

Descriptive statistical procedure and evaluations were done to analyse the results. Chi-square test and Fisher's exact test were applied and ' $p$ ' value determined accordingly. All the relevant statistical methods were carried out using SPSS (Statistical Package for the Social Sciences) for Windows (Version 17.0)

\section{Results and Analysis}

This study is a prospective study done from January 2014 to January 2015 at King George Hospital, Visakhapatnam.

\section{Patient Demographics}

Out of 265 patients who underwent UGI endoscopy after being diagnosed of GERD, 200 patients satisfying the inclusion criteria were selected for the study.

The study involved 122 males (61\%) and 78 females (39\%). Most of the patients $149(74.5 \%)$ were in the $30-60$ year age group. This was followed by $32(16 \%)$ in the $>60$ years age group and $19(9.5 \%)$ in the $<30$ years age group. Similar population based study was done by Locke GR study.(1)

\begin{tabular}{|c|c|c|}
\hline Gender & Frequency & Percentages (\%) \\
\hline Male & 122 & 61 \\
\hline Female & 78 & 39 \\
\hline Total & $\mathbf{2 0 0}$ & $\mathbf{1 0 0 . 0}$ \\
\hline \multicolumn{3}{|c|}{ Table 1: Sex Distribution } \\
\hline
\end{tabular}

\begin{tabular}{|c|c|c|}
\hline Age Groups & Frequency & Percentages (\%) \\
\hline$<30$ Years & 19 & 9.5 \\
\hline 30-60 Years & 149 & 74.5 \\
\hline$>60$ Years & 32 & 16 \\
\hline Total & $\mathbf{2 0 0}$ & $\mathbf{1 0 0 . 0}$ \\
\hline \multicolumn{2}{|c|}{ Table 2: Age Group Distribution } \\
\hline
\end{tabular}

\section{Symptomatology}

Belching was the most commonly experienced complaint with 192 (96\%) patients having it, followed by heartburn 184 (92\%) and acid regurgitation 180 (90\%) respectively. 101 $(50.5 \%)$ patients had symptoms of abdominal pain and $62(31 \%)$ had water brash. Vomiting was seen in $37(18.5 \%)$ patients and $4(2 \%)$ patients complained of dysphagia. Symptomatic study was similar in Klauser AG study.(2)

\begin{tabular}{|c|c|c|}
\hline Symptoms & Frequency & Percentages (\%) \\
\hline Heart Burn & 184 & 92 \\
\hline Regurgitation & 180 & 90 \\
\hline Dysphagia & 4 & 2 \\
\hline Abdominal Pain & 101 & 50.5 \\
\hline Belching & 192 & 96 \\
\hline Water Brash & 62 & 31 \\
\hline Vomiting & 37 & 18.5 \\
\hline \multicolumn{2}{|c|}{ Table 3: Symptomatology } \\
\hline
\end{tabular}

\section{Habits}

$44(22 \%)$ patients gave history of smoking and $31(15.5 \%)$ consumed alcohol. Nocon M conducted a study on lifestyle factors in 2006 which showed increased prevalence of GERD with alcoholism. (3)

\section{Drug Use}

21(10.5\%) patients had history of chronic drug intake in the recent past for periods ranging from 2 months to 90 months. The drugs that were being used were antiplatelet drugs $8(4 \%)$, NSAIDs $7(3.5 \%)$, steroids $3(1.5 \%)$ and other drugs $3(1.5 \%)$. Kotzan J, Wade showed prescription of NSAID is a predisposition factor for GERD.(4)

\section{Body Mass Index}

Out of $200,108(90 \%)$ patients had a $\mathrm{BMI}<25$ and remaining $20(10 \%)$ had BMI $>25$. Hampel and Abraham Study showed increased GERD risk with obesity.(5)

\section{Waist-to-Hip Ratio}

The upper limit of normal was taken as 1 in males and 0.8 in females accordingly. 127(63.5\%) patients had normal ratio whereas 73(36.5\%) were classified as obese.

\section{Co-existing Medical Illness}

$20(10 \%)$ patients had chronic obstructive pulmonary disease (COPD), 5(2.5\%) had bronchial asthma, 12(6\%) had Ischaemic heart disease (IHD) and 6(3\%) had diabetes mellitus (DM). 


\section{Endoscopy Report}

On upper GI endoscopy, 78(39\%) patients had lesions suggestive of oesophagitis. Biopsy was done in all patients with oesophageal lesions and sent for histopathological analysis. $10(5 \%)$ patients had evidence of Barrett's oesophagus, i.e., abnormal change in the epithelium lining of lower oesophagus from squamous cell to columnar cell lining (Metaplasia). One patient had an oesophageal lesion which was proved to be adenocarcinoma on histopathology. All the patients with Barrett's oesophagus and adenocarcinoma were above 45 years of age.

Hiatal hernia was seen in $18(9 \%)$ of patients. $14(7 \%)$ patients had evidence of gastritis and/or duodenitis with/without ulcers. One patient had diffuse white raised plaques indicating oesophageal candidiasis, which was proved on culturing the biopsy specimen.

\begin{tabular}{|c|c|c|}
\hline Endoscopy Report & Frequency & Percentages (\%) \\
\hline Lesion Present & 78 & 39 \\
\hline Lesion Absent & 122 & 61 \\
\hline Total & 200 & 100.0 \\
\hline $\begin{array}{c}\text { Table } 4 \\
\text { based or }\end{array}$ & $\begin{array}{l}\text { sificatio } \\
\text { Endosce }\end{array}$ & $\begin{array}{l}\text { Patients } \\
\text { Findings }\end{array}$ \\
\hline
\end{tabular}

\begin{tabular}{|c|c|c|}
\hline Associated & Frequency & Percentages (\%) \\
\hline Lesions/Findings & & \\
\hline Hiatal Hernia & 18 & 9 \\
\hline Gastritis/Gastric Ulcer & 8 & 4 \\
\hline Duodenitis/Duodenal Ulcer & 2 & 1 \\
\hline Gastritis + Duodenitis & 4 & 2 \\
\hline Oesophageal Candidiasis & 1 & 0.5 \\
\hline \multicolumn{2}{|c|}{ Table 5: Associated Lesions/ } \\
\hline \multicolumn{2}{|c|}{ Findings found on UGI Endoscopy } \\
\hline
\end{tabular}

On correlation/linear regression analysis, correlation was found between the severity of symptoms of acid regurgitation and endoscopic findings $(\mathrm{p}=0.039)$. However, there was no correlation between the severity of heartburn, the other important symptom and endoscopic finding $(\mathrm{p}=0.311)$.

Among the other symptoms, only water brash had a significant correlation with positive endoscopic findings ( $\mathrm{p}=0.033)$.

Alcohol consumption had a significant correlation $(\mathrm{p}=0.049)$, whereas smoking didn't show correlation $(\mathrm{p}=0.09)$.

History of drug intake also didn't show any significant correlation $(p=0.928)$.

Increased BMI $(>25)$ was found to have significant correlation with positive endoscopic findings $(\mathrm{p}=0.03)$.

On considering the waist-to-hip ratio, there was significant correlation between obesity and positive endoscopic findings $(\mathrm{p}=0.04)$.

\section{DISCUSSION}

Symptomatic gastro-oesophageal reflux is one of the commonest problem encountered by physicians. The prevalence of reflux and its primary symptom, heartburn in general population is extremely difficult to obtain as many patients consider this sensation as normal and do not seek medical attention. The magnitude of the problem is further increased by the observation that GERD can masquerade as typical chest pain, angina or present with pulmonary symptoms particularly in children.

In this particular study, we sought to explore the symptomatology of GERD, correlation with endoscopic findings along with contribution of risk factors to endoscopically proved erosive lesions and also the incidence of Barrett's oesophagus in the population group that was selected for the study.

Most of the observations made in this study correlated well with earlier studies. Several studies in the past have suggested that the relation between symptoms of GERD and endoscopic findings are highly variable. Endoscopic findings in patients with GERD have ranged as widely as from $10 \%$ to $70 \%$ and, interestingly, these findings have been recorded even in $8 \%$ of asymptomatic individuals (108). In our study which involved 200 patients, 78 patients (39\%) had oesophageal lesions on endoscopy.

In our study also, majority of the patients were males $(61 \%)$ and in the age group $>30$ years $(90.5 \%)$.

The most common symptoms associated with GERD are heartburn and regurgitation. The present study also showed heartburn and regurgitation in $92 \%$ and $90 \%$ of the patients respectively. Most patients described heartburn as burning sensation in retrosternal area spreading from epigastrium.

Another important symptom which was seen in majority of the patients with GERD is belching ( $96 \%$ in our study) which cannot be taken as a discriminatory symptom of GERD as it can also be seen in dyspepsia of all causes.

Abdominal pain, especially in the epigastric region was reported in nearly half of our patients. Water brash was observed in $31 \%$ of our patients. Water brash is supposed to be induced by acid reflux wherein oesophageal acid triggers an oesophago-salivary reflux. Although increase of salivation accompanies acid reflux in most patients with reflux oesophagitis, the response is markedly exaggerated in some patients. GERD accompanied by regurgitation and aspiration may cause respiratory symptom such as non-seasonal asthma, recurrent pneumonia, nocturnal choking and morning hoarseness. In the present study, respiratory symptoms were observed in 25 cases(12.5\%), 20 of which had chronic obstructive pulmonary disease and 5 of them had bronchial asthma (BA). Parsons Jonathan $\mathrm{P}$ in his current opinion in pulmonary medicine also showed increased risk of GERD in asthma and COPD.(6)

Obesity is considered to be a predisposing factor for GERD and weight reduction is usually helpful in reducing the symptoms. Both BMI and WHR indicating obesity showed significant correlation with oesophagitis in our study.

In the present study; however, only 20 patients $(10 \%)$ were found to be overweight (i.e., BMI>25). Waist-to-hip ratio (WHR) measurements, which is considered a better indicator of obesity, showed 73 patients (36.5\%) in the obese category.

Smoking and alcohol are considered to have inhibitory effect on lower oesophageal sphincter (LES), thus promoting reflux. In this study, 44 patients (22\%) were smokers.

The role of drugs causing GERD symptoms is well known. However, in our study, only a small proportion of patients had history of chronic drug use (10.5\%).

The relationship between sliding hiatal hernia and the genesis of oesophagitis remains slightly controversial. In the present study, 18 patients (9\%) had sliding hiatus. Ronkainen showed high prevalence of gastrooesophageal reflux symptoms in Sweden population with oesophagitis,(7) which is a reversal from our study. 
In the present study of gastro-oesophageal reflux disease, 10 cases $(5 \%)$ were diagnosed as Barrett's oesophagus based on histopathological reports. In the presence of Barrett's oesophagus, changes of oesophagitis were usually severe as it was seen in 6 of our cases. But 4 of them had mild oesophagitis or normal mucosa. Endoscopic examination indicates Barrett's oesophagus by the presence of velvety red mucosa in the distal oesophagus.

The causal relation between GERD and oesophageal carcinoma is proven in many studies. The incidence of adenocarcinoma in Barrett's oesophagus is around 10\%. In our study, one of the patient (0.5\%) had adenocarcinoma, which was proved by histopathology. Liberman DA conducted community based study and showed increased incidence of Barrett's in GERD.(8) Similarly, Kopert conducted a molecular biology of oesophageal adenocarcinoma and confirmed increased incidence in GERD.(9)

\section{CONCLUSION}

1. The common presenting symptoms of GERD are heartburn (92\%), acid regurgitation (90\%), belching (96\%) and abdominal pain (50.5\%).

2. There is poor association between the severity of symptoms of GERD and presence of erosive lesions (oesophagitis) on endoscopy. Among the symptoms, only acid regurgitation $(\mathrm{p}=0.039)$ and water brash $(\mathrm{p}=0.033)$ showed significant correlation with endoscopic findings.

3. Increased WHR ( $p=0.04)$ and increased BMI $(p=0.03)$ had significant correlation with endoscopy positive GERD.

4. Among other risk factors, only alcohol consumption $(p=0.049)$ showed a positive relation with reflux oesophagitis.

5. Barrett's oesophagus [Gastrooesophageal junction metaplasia] was seen in 5\% of the GERD patients in this study. One patient had evidence of oesophageal adenocarcinoma on biopsy.

6. One patient had lesions suggestive of oesophageal candidiasis, a fungal infection.

7. Hiatal hernia was present in $9 \%$ of the total patients.

\section{Finally, by this study, it is concluded that}

Symptomatic GERD may not be associated with endoscopic evidence of oesophagitis and reinforced the fact that NERD (Non-erosive reflux disease) is a common entity, which forms a considerable proportion of patients seeking medical attention for reflux symptoms. However, since the patients with Barrett's oesophagus are at a higher risk of developing adenocarcinoma, it is suggested that all patients with gastrooesophageal reflux symptoms should be subjected to upper GI endoscopy and biopsy to determine the presence of Barrett's oesophagus.

\section{REFERENCES}

1. Locke GR, Talley NJ, Fett SL, et al. Prevalence and clinical spectrum of gastroesophageal reflux: a population based study in Olmsted County, Minnesota. Gastroenterology 1997;112(5):1448-56.

2. Klauser AG, Schindlbeck NE, Muller-Lissner SA. Symptoms in gastro-oesophageal reflux disease. Lancet 1990;335(8683):205-8.

3. Nocon M, Labenz J, Willich SN. Lifestyle factors and symptoms of gastroesophageal reflux-a population based study. Aliment Pharmacologic Therapy 2006;23(1):16974.

4. Kotzan J, Wade W, Yu HH. Assessing NSAID prescription user as a predisposing factor for GERD in Medicaid population. Pharmac Res 2001;18(9):1367-72.

5. Hampel H, Abraham NS, El-Serag HB. Meta-analysis: obesity and the risk for gastroesophageal reflux disease and its complications. Ann Intern Medicine 2005;143(3):199-211.

6. Parsons JP, Mastronarde JG. Gastroesophageal reflux disease and asthma. Current Opinion in Pulmonary Medicine 2010;16(1):60-3.

7. Ronkainen J, Aro P, Storskrubb T, et al. High prevalence of gastroesophageal reflux symptoms esophagitis with or without symptoms in general adult Swedish population. A Kalixanda study report. Scand J Gastroenterol 2005;40(3):275-85.

8. Lieberman DA, Oehlke M, Helfand M. Risk factors for Barrett's esophagus in community based practise. Gorge consortium. Gastroenterology outcomes research group in endoscopy. Am J Gastroenterology 1997;92(8):1293-7.

9. Koppert LB, Wijnhoven BP, van Dekken $\mathrm{H}$, et al. The molecular biology of esophageal adenocarcinoma. J Surg Oncol 2005;92(3):169-90. 